\title{
Assessment of Casualties in a Chemical Environment
}

\author{
Capt P B Hodson, \\ $M B, C h B, R A M C(V)$
}

SUMMARY: A trial is reported in which RAMC staff working in a dressing station and wearing full NBC Individua Protective Equipment (IPE), attempted to take pulse and blood pressure (BP) readings on casualties similarly clad. These basic parameters however, were obtained from only half the casualties, the time taken to obtain them was prohibitiv $\$$ and the blood pressures were inaccurate.

Certain remedies are discussed but until existing equipment is modified casualties are best evacuated directly to a protected unit or out of the contaminated zone.

\section{Introduction}

The author was in Germany as a reserve officer attached to a dressing station during the recent Exercise Lionheart, when an incident occurred which provoked much discussion.

The unit, a light dressing station, was in full Individual Protection Equipment (IPE), when 20 notional casualties, the majority affected by nerve gas, were admitted. Each casualty's field medical record gave his temperature, pulse and BP, which raised two basic questions. Firstly, how could these vital signs be elicited without endangering either those taking them or further contaminating the casualty, and secondly how reliable were these readings likely to be?

After discussion it was felt that the casualty's temperature could not be safely obtained but that it may be possible to take the pulse and BP. A trial was set up in which two members of the unit took the pulse and BP of volunteer casualties.

\section{Method}

In the first part of the trial each Combat Medical Technician (CMT) took readings from 13 people, with both CMTs and casualties in shirt sleeves, the results being recorded in Table I. The table shows a good measure of agreement between the readings, and this part of the trial took 50 minutes.

\begin{tabular}{|c|c|c|c|c|}
\hline \multirow[b]{3}{*}{ Casualty } & \multicolumn{3}{|c|}{$\begin{array}{c}\text { Table I } \\
\text { Under Normal Conditions }\end{array}$} & \\
\hline & \multicolumn{2}{|c|}{ Pulse } & \multicolumn{2}{|c|}{$\mathbf{B P}$} \\
\hline & Medic 1 & Medic 2 & Medic I & Medic 2 \\
\hline 1 & 82 & 70 & $110 / 70$ & $120 / 90$ \\
\hline 2 & 72 & 80 & $120 / 70$ & $120 / 60$ \\
\hline 3 & 67 & 90 & $120 / 90$ & $110 / 70$ \\
\hline 4 & 87 & 80 & $110 / 60$ & $115 / 70$ \\
\hline 5 & 74 & 82 & $120 / 80$ & $105 / 70$ \\
\hline 6 & 82 & 74 & $130 / 90$ & $110 / 80$ \\
\hline 7 & 100 & 100 & $120 / 80$ & $100 / 65$ \\
\hline 8 & 101 & 100 & $100 / 60$ & $120 / 80$ \\
\hline 9 & 86 & 92 & $115 / 90$ & $100 / 85$ \\
\hline 10 & 77 & 82 & $120 / 70$ & $125 / 65$ \\
\hline 11 & 98 & 92 & $110 / 80$ & $100 / 75$ \\
\hline 12 & 70 & 74 & $110 / 90$ & $110 / 80$ \\
\hline 13 & 78 & 60 & $110 / 75$ & $100 / 80$ \\
\hline
\end{tabular}

In the second part of the trial it was assumed that $i$ the dressing station, a conventional type, i.e. without collective protection liner affording protection agains? chemical contamination, both casualties and CMTs weres wearing IPE.

Earlier attempts by the author to take radial pulsesi whilst wearing two pairs of gloves had proved fruitless and so the CMTs were instructed to take carotid pulses on the casualties; this they did by first decontaminatipgtheir own gloves and the casualty's hood prior to loosect ing the drawstring of the hood and inserting their gloped hand into the hood to take the pulse.

To take the BP, the CMT first decontaminated $\mathbb{T i}$. gloves, hood and stethoscope earpieces before slippgigo the earpieces under his hood. Then having decon taminated the casualty's cuff prior to loosening it, 负D CMT slipped the decontaminated diaphragm of the stethoscope (which had to be of the Littman type) unde 5 the casualty's shirt sleeve and worked it up his arm untif it lay over the brachial artery. The sphygmomanomete cuff was placed around the arm in the normal manne but over the IPE. The results can be seen in Table II

Table II

Wearing full NBC Protection

\begin{tabular}{lcccc} 
& \multicolumn{2}{c}{ Pulse } & \multicolumn{2}{c}{ BP } \\
Casualty & Medic 1 & Medic 2 & Medic I & Medic 2 \\
1 & $N / R$ & 60 & $130 / 90$ & N/R \\
2 & 55 & 64 & $130 / 90$ & N/R \\
3 & $N / R$ & 70 & $130 / 90$ & $120 / 60$ \\
4 & 65 & $N / R$ & $N / R$ & $130 / 100$ \\
5 & 66 & N/R & $130 / 90$ & N/R
\end{tabular}

A halt was called to the proceedings after forty minutes by which time only five casualties had been processed $b$ 疋 each CMT and the CMTs were becoming exhausted be their exertions.

Table III compares the average BP readings wher available, taken on the same casualty in both parts of the trial.

\section{Discussion}

Despite the precautions taken against contamination when obtaining these readings, the procedures put botk 
Table III

Average Readings

$\begin{array}{ccl}\text { Casualty } & \text { Table I } & \text { Table II } \\ 1 & 115 / 80 & 130 / 90 \\ 2 & 120 / 65 & 130 / 90 \\ 3 & 115 / 80 & 125 / 75 \\ 4 & 110 / 65 & 130 / 100 \\ 5 & 110 / 75 & 130 / 90\end{array}$

CMT and casualty at risk, and therefore cannot be recommended.

The reliability of the parameters is low, with no reading obtained in approximately half the cases despite the fact that the trial was conducted in ideal conditions on fit and healthy men. No attempt was made to verify the trial statistically, the object being simply to demonstrate the practical difficulties facing the clinician. There can be no doubt however that near a combat zone at night under the threat of conventional and chemical attack, and with possibly uncooperative and shocked casualties with rapid, feeble pulses and low blood pressures, even the poor results obtained in this trial could not be attained.

If the time taken for the second part of the trial is extrapolated, it would mean that at best such a unit could only process a percentage of the total workload in 24 hours. Even assuming that the CMTs could continue to work at the same rate in these conditions they would manage to obtain readings from only half of the casualties. It also needs to be emphasised that the trial had involved no attempt at treatment, which would be difficult to envisage under conditions where virtually no clinical information was available.

A sphygmomanometer bladder which is relatively too small may give falsely high pressures ${ }^{\prime}$. In the second part of the trial there is an average increase of $15 \mathrm{~mm} \mathrm{Hg}$ in both systolic and diastolic pressures. This increase may be at least partly artefactual because the cuff was placed around the arm over a minimum of three thicknesses of clothing (combat shirt and jacket, IPE jacket and in some, a jersey) ${ }^{2}$. This "cuff hypertension" can be eliminated by the simple expedient of using a larger size sphygmomanometer cuff in which the bladder is $36 \mathrm{cms}$ long?.

An accurate BP is vital if there is to be any attempt to assess an injured casualty. Differentiation between chemical injury and battleshock will be difficult without accurate vital signs bearing in mind that it is anticipated that $20 \%$ of all casualties will be suffering from battleshock with a possibility of this figure rising as high as $50 \%{ }^{3,4}$.

Bennion in his paper ${ }^{5}$, suggests modifications to protective clothing in order to facilitate the taking of temperature, pulse and BP readings in conjunction with the use of an electronic thermometer and stethoscope. The ' modifications to the equipment were his suggestions onIv and had not heen tected. hut acsured maintenance of protection for both casualty and CMT as well as promising reliable clinical information.

\section{Conclusion}

A casualty decontamination facility must be attached to a unit with a protective liner in which casualties can be examined normally. Alternatively some modifications to existing equipment must be made.

Admission of a casualty to a unit under the conditions of the trial serves no useful purpose, causes delay and poses a danger to both casualty and CMT.

\section{REFERENCES}

1. O'Brien E T and O'Malley K ABC of Blood Pressure Measurement: The Sphygmomanometer. Br Med J 1979; 2: 851-853.

2. O'Brien E T and O'Malley K ABC of Blood Pressure Measurement: The Patient. Br Med J 1979; 2: 920-921.

3. BRooking J I Potential Psychological Problems of Army Medical Services personnel in combat with particular reference to the Territorial Army. J R Army Med Corps 1983; 129: 146-153.

4. Cadigan F C Jr. Battleshock - The Chemical Dimension J R Army Med Corps 1982; 128: 89-92.

5. BENNION S D Designing of NBC Protective Gear to allow for Adequate First Aid. Milit Med 1982; 147: 960-962.

\section{Vital Signs Monitoring in a Chemical Environment}

\section{From Major General D M Roberts OHP, MD, FRCPE, MRCP}

It has long been suspected that it would be difficult to obtain reliable pulse, blood pressure and temperature recordings from casualties wearing full Individual Protective Equipment (IPE) without breaching that protection. It would be even more difficult if the medical attendant was similarly clad. It would be virtually impossible, using conventional techniques, if the casualty was also enclosed within a casualty bag. Under the latter circumstances it might also be difficult to obtain a recording of the respiration rate.

These suspicions have derived largely from a priori reasoning and from anecdotal experience, rather than from properly conducted field trials. The paper by Hodson goes some way towards confirming these suspicions. Hodson's controlled trial was a severely limited one but, notwithstanding its vulnerability under close statistical analysis, the thrust of the paper comes across very nicely. If we are to measure vital signs in casualties in a chemical environment a whole new approach needs to be devised.

One current initiative in this field is a programme to develop a "Bag, Patient Nursing, Chemical Protection", the intended purpose of which is to allow urgent nursing procedures to be carried out under overhead cover and 
to provide "easy access to the casualty to deal with medical or surgical emergencies". There is no present indication as to how this might be achieved, but it is obvious that it cannot be achieved without some breach of chemical protection. More relevant to the problem of monitoring vital signs is the additional stated intention that the design of the bag should permit intravenous treatment through appropriate tubing, "and the connection of monitors to the body." It is no concern of the programme, however, as to how the monitoring might be achieved.

It is important to realise that field medical units at most echelons may not be subject to a chemical hazard continuously for very long periods of time. The requirement not to breach IPE and casualty bags in order to record vital signs may operate only intermittently. Nevertheless, the problem has to be faced.

Before attempting to provide an answer to this problem we should ask ourselves several questions. Why do we need to know these parameters? Which signs are the most important under given circumstances? Is a knowledge of these vital signs important for every casualty or just a proportion of them? If the latter, then how do we decide which ones need monitoring?

Given that special techniques are going to be necessary to monitor any vital signs at all, it is axiomatic that, in a heavy casualty loading under chemical warfare conditions, and working to the principle of providing life saving care for the largest possible number with the limited facilities available, we can expect to monitor only a proportion of casualties. Which ones?

As casualties pass rearwards along the evacuation chain some will require life saving intervention. These will usually be graded P1. It is important to remember, however, that priorities may change with time. A P2 casualty may require upgrading to $P 1$. The condition of an inherently unstable P1 casualty may suddenly deteriorate, necessitating urgent intervention. The prime role of monitoring, therefore, is to detect deterioration in the clinical condition of a casualty sufficient to indicate a need for early intervention. All Pl casualties should therefore be monitored and, if possible, a few of the more severe $\mathrm{P} 2$ casualties.

Which signs do we need to record? For the majority of casualties in a heavy casualty loading, urgent revision of management decisions will depend on the answer to two questions. Is the casualty breathing and adequately oxygenated? Is the peripheral circulation adequate to sustain good tissue perfusion?

There is no method applicable under battlefield conditions of determining oxygenation other than the colour of the patient. It may be possible to discern significant cyanosis through the window of the casualty bag but not if the casualty is wearing a respirator. A knowledge of the respiratory rate would provide indirect evidence of respiratory status.

A knowledge of the pulse rate and blood pressure is vital. Between them they provide a rough guide to the likely state of tissue perfusion; certainly no better guige will be available.

The body surface temperature is too dependent upen skin perfusion to be of much use in potentially shocked casualties. The determination of core temperature poses too many technical problems to justify its further co sideration. In any case, a knowledge of temperatureas not vital to the vast majority of clinical management degisions requiring to be made for casualties within the first day or so after injury.

The policy aim, therefore, should be to have the abitid ty to monitor pulse, blood pressure and respiration in $\$$ $\mathrm{P} 1$ casualties and, if possible, a small proportion of $\overline{\mathrm{B} 2}$ casualties. These casualties will require monitoring whisgt on the move in motor ambulances and ambulance trains, and whilst at field medical units.

How can this monitoring be achieved? Hodson has shown that it cannot be done realistically by conventignal

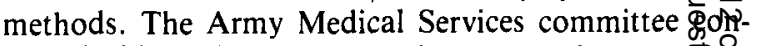
cerned with NBC problems has been aware for sometime of a need to develop techniques to meet this challgnge and has appointed a small Working Group to exa留e the problem. The main conclusion of the Working Gofog so far is a chastening one - that the problem is a e e y difficult one which will probably require funding of research and development programme for its solugog.

A Canadian device for the measurement of braghial blood pressure by use of a clamp applied outsid casualty bag, but requiring use of an acoustic stethosto by the attendant, seems impractical without modification. It might be useful if it could be combined with a pufge transducer attached to the hand or to a finger, amd capable of detecting obliteration of the pulse as an $\overrightarrow{\mathbf{B}}$ dication of systolic blood pressure.

The pulse itself might be measured by a piezo-elect画 crystal plethysmography transducer attached, say, to finger. The transducer might drive a small light-emittimg diode (LED) display which would give a small flash 站 light synchronous with the pulse and visible through 通e casualty bag window. Alternatively, a liquid crys display (LCD) might be better in view of its very smఖll power requirement. It is even possible that an LCD might be powered directly by the transducer itself without the need for an independent power source.

The respiration rate might best be measured by transthoracic impedance method using two ECG elecetrodes suitably positioned on the chest. There would be no question of connection to a recorder or oscilloscose display device, of course, although it could be connected to the same display device as that used for the pulse

An alternative method of display, capable of linkage to both pulse and respiration devices, but one whife would certainly require an independent power sourke, would be an acoustic device capable of undulating a faed frequency audible tone. Any system requiring an independent vower sunnlv would nose nroblems relating 
to storage, turnover and replacement of batteries.

One other method under consideration is a "doll's eye" display activated by a pulse/respiration transducer driven pneumatically by a small air-filled balloon.

At the end of the day, any system developed must be cheap (and most of the devices described would be surprisingly so), simple to apply (the ones described are only moderately so), and capable of being stored in a pocket on the outside of a proportion of casualty bags. No such system exists at present.

Much more work is going to have to be done before this problem is solved. There will be much further debate and this is to be welcomed. Perhaps some of it might take place in the columns of this Journal.

D M ROBERTS

\section{Reports of Meetings}

\section{Association of Service Physicians}

The sixth Annual Meeting of the Association of Service Physicians was held at the Royal Army Medical College, Millbank on 15 February 1985; 37 members attended.

The first session, chaired by Surg Capt J M Beeley, RN Consultant Adviser in Medicine, opened with a paper by Surg Lt Cdr C R Kershaw on Sudden Infant Death in Gosport, in which he presented an analysis of the cases of sudden infant death in civilian and Service families, which occurred in the Gosport area in the period 1977-81. The incidence was found to be higher than in the rest of UK and neighbouring Southampton, and varied in the different housing estates; social and economic factors correlated with these differences. There was a peak occurrence in the winter months (December-March), a pronounced male preponderance, and a higher occurrence in single parent families. Few of the children who died had been breast fed. Following the survey a scheme for closer monitoring by health visitors of families judged to be at risk had been instituted, as in other parts of the country, and there appeared now to be some reduction in the incidence of this disastrous condition.

This was followed by a paper by Major R Whiteoak on the Management of Service Patients with Fits. All Army Consultant Physicians and Senior Specialists in Medicine had been circulated with the case histories of 10 patients who had suffered one or more fits; their opinions were sought regarding aspects of investigation, management, and particularly the Pulheems grading and employment standard of each case.

Replies had indicated a wide diversity of opinion, particularly with regard to some of the gradings and employ- ment standards. The paper stimulated considerable animated discussion, and it was suggested that firmer guidelines should be produced to try to ensure more coneo sistency in the management and grading of such patients $\frac{\vec{D}}{N}$ in future.

After a short interval, the second session, chaired by Maj Gen D M Roberts, Director of Army Medicine opened with a paper by Surg Cdr W M Edmonstone or the Use of Laser Phototherapy in the Treatment of Lunga Cancer. After a brief outline of the basic physics of lasers Commander Edmonstone went on to describe his ex $\varnothing$ perience of laser therapy for the resection of endobrono chial tumours causing partial or complete bronchiat. obstruction with distal atelectasis and increasinge breathlessness, and the arrest of bronchial haemorrhage: Such therapy may often afford useful palliative symptomatic relief for patients who have had previous radiotherapy or chemotherapy.

The final paper was by Major M J World on the Duodenal Mucosal Response to Gastric Acid Hypersecretion. He reported the finding of metaplastic gastric-type mucosa, incorporating parietal cells in resting phase, in the duodenal bulb of a proportion of "normal" individuals, but more commonly in patients with duodenal or pre-pyloric ulceration, or those without ulceration who had a high peak acid output on secretion studies. Metaplasia had been seen to regress following vagotomy. These changes had been found in some patients presenting with abdominal pain or upper gastro-intestinal haemorrhage in whom other investigations proved negative, and a study was planned to assess the affects of medical acid lowering treatment regimes in the management of this group of patients.

(Submitted by LT Col T B N OldREY, Secretary of the Association) 